\title{
Age Related Hearing Loss and Tinnitus - Nipping a Budding Epidemic
}

Akeem Olawale Lasisi ${ }^{*}$

Otorhinolaryngology, College of medicine University of Ibadan, Ibadan, Nigeria

*Corresponding author: Akeem Olawale Lasisi, College of medicine University of Ibadan, Otorhinolaryngology, Po Box 22040 University of Ibadan, Ibadan, Nigeria, Tel: 2347031697079; E-mail: akeemlasisi@gmail.com

Rec date: Jun 30, 2015; Acc date: Jul 20, 2015; Pub date: Jul 23, 2015

Copyright: (c) 2015 Lasisi AO. This is an open-access article distributed under the terms of the Creative Commons Attribution License, which permits unrestricted use, distribution, and reproduction in any medium, provided the original author and source are credited.

\section{Introduction}

The marginal improvement in the health care provision with the accompanying increase in lifespan has led to emergence non communicable diseases in developing countries. Among these, chronic tinnitus and hearing loss have prominent; in Nigeria a prevalence of $6.1 \%$ and $14.0 \%$ respectively have been reported among elderly people greater than $65 y$ years of age $[1,2]$. The resulting loss of quality of life, impaired activity of daily living and negative perception of life also make hearing impairment and tinnitus a great burden to the sufferers, dependents and the health care. The economic impact of tinnitus on the general population has not been estimated to date, but the urgency of understanding the underpinnings of tinnitus is illustrated by $\$ 190$ million in compensation payments awarded in 2004 to US veterans with tinnitus as their major disability [3]. Previous studies have revealed suppurative otitis media, hypertension and head injury among other risk factors as significant $[1,2]$. The identified risk factors were preventable or controllable; thus underscoring the role of public health methods in the control of elderly tinnitus and hearing loss and improvement in the quality of life of these people. The biology of tinnitus and hearing loss showed that serum Folate was significantly lower among elderly with ARHL while low plasma melatonin and vitamin B12 have significant correlation with the development of subjective idiopathic tinnitus among the elderly [4,5]. These finding suggests that the correction of these nutritional markers may be useful in the reversal of tinnitus and age related hearing loss. The prominent role of the serotonergic system in auditory perception and in the etiology of tinnitus has also been reported [6] It is also significant observation that among these elderly people with hearing loss, none of them was on any hearing aid fitting for to augment their hearing and in deed, only an insignificant proportion has presented for evaluation. These findings have several significant implications. Firstly, it shows that complaints of tinnitus and hearing loss are probably assumed by the people not to be a disease, possibly thought to be normal accompaniments of ageing, so there is probably no need to look for treatment. Secondly, support for hearing among the elderly in terms of provision of hearing is still non-existent. The provision of hearing aids to the elderly with age related hearing loss is particularly important because it can improve their hearing and reduce the negative effects of the sequela. There is the need to make provision for the hearing aid as an integral part of the care of the elderly population in the various
National Health Insurance Scheme in the low and medium income countries, especially in the sub Saharan Africa. In addition, there is a need to intensify research into the biology of age related hearing loss. There has been evidence of the disease running in family suggesting that familial pattern and role of heredity and genetics need to be studied in order to gain deeper insight into disease.

It is expected that gene mutation responsible for age related hearing loss may differ among the diverse population globally. Mutated gene and the chromosomal locus which have been linked with tinnitus and age related hearing loss include among others DSPP (4q21), MFN2 (1p36), SDHD (11q23), NF2 (22q12), SDHC (1q21), SDHB (1p36), CACNA1A (19p13), VHL (3p25), NAGA (22q11), WFS1 (4p16), COL1A1 (17q21), COL1A2 (7q22), GLA (Xq22), COCH (14q12) [7].

The comparison of these mutations reported in other populations will help provide evolutionary context; in addition, the knowledge of this will further help in understanding pathway to development of disease and provide useful input for screening panels in African ancestry populations and improving genetic counseling.

\section{References}

1. Lasisi OA, Abiona TA, Gureje O (2010) The Prevalence and correlates of self-reported hearing impairment from the Ibadan Study of Ageing. Trans Roy Soc Trop Med Hyg 104: 518-23.

2. Lasisi OA, Abiona TA, Gureje O (2010) Tinnitus in the elderly: Profile, correlates, and impact in the Nigerian Study of Ageing. OtolaryngologyHead Neck Surg 143: 510-515.

3. Henry JA, Dennis KC, Scechter MA (2005) General review of tinnitus: prevalence, mechanisms, effects, and management. J. Speech Lang Hear Res 48: 1204-1235.

4. Lasisi OA, Fehintola FA, Yusuf OB (2010) Age related hearing loss, vitamin B-12 and Folate in the elderly. Otolaryngology-Head and Neck Surg 143: 826-830.

5. Lasisi OA, Fehintola FA, Lasisi TJ (2012) The role of plasma melatonin and vitamins in the development of idiopathic Tinnitus among the elderly. Ghana Med Journal 3: 152-257.

6. Simpson JJ, Davies WE (2000) A review of evidence in support of a role for 5-HT in the perception of tinnitus. Hear Res 145: 1-7.

7. Sand PG, Langguth B, Kleinjung T, Eichhammer P (2014) Genetics of tinnitus. Progress in Brain Research 166: 159-168. 